\title{
Prevalence and Reasons for Tooth Loss in a Sample from a Dental Clinic in Brazil
}

\author{
Andréia Affonso Barretto Montandon, ${ }^{1}$ Elizangela Partata Zuza, ${ }^{2}$ \\ and Benedicto Egbert Corrêa de Toledo ${ }^{1,2}$ \\ ${ }^{1}$ Department of Social Dentistry, São Paulo State University (UNESP), Rua Humaitá, 1680, 14801-903 Araraquara, SP, Brazil \\ ${ }^{2}$ Department of Master of Dental Sciences, Educational Foundation of Barretos (UNIFEB), Avenida Prof. Roberto Frade Monte 389, \\ 14783-226 Barretos, SP, Brazil
}

Correspondence should be addressed to Elizangela Partata Zuza, elizangelazuza@yahoo.com.br

Received 20 April 2012; Accepted 24 July 2012

Academic Editor: Jose Roberto Cortelli

Copyright () 2012 Andréia Affonso Barretto Montandon et al. This is an open access article distributed under the Creative Commons Attribution License, which permits unrestricted use, distribution, and reproduction in any medium, provided the original work is properly cited.

\begin{abstract}
Purpose. To evaluate the prevalence and reasons for teeth extractions in a sample from a dental clinic in Brazil. Methods. The prevalence of teeth mortality was analyzed by gender, age, tooth type and reasons for extraction on 800 teeth of 439 subjects, whose data was collected in clinical records in a convenience sample. Results. The groups with range from 35 to 44 years, 45 to 54 years and 55 to 64 years revealed significantly greater number of teeth extractions than other age groups $(P<0.0001)$. The anterior teeth loss increased significantly with aging, while the tooth mortality of premolar and molar were higher in younger people. The caries was the more prevalent reason for tooth mortality among young and adults up to 44 years old, while the periodontal disease was the main reason for extractions from 45 years old until range of 81 years $(P<0.0001)$. Conclusions. It can be suggested that some reasons for tooth loss were age-dependent, but the caries and the periodontal diseases were the main reasons for tooth mortality in this Brazilian sample.
\end{abstract}

\section{Introduction}

Studies concerning the epidemiology in dentistry have showed that dental caries and periodontal diseases are the most prevalent pathologies that affect the oral cavity. Previous studies performed by American researchers had suggested that dental caries was the main reason for teeth extraction, and other studies accomplished in New Zealand, Sweden, and even in Brazil confirmed that caries may lead to tooth mortality [1-5]. On the other hand, some studies suggested that periodontal disease was the most prevalent reason that leads to tooth loss. Thus, controversial findings could be explained by differences in the characteristics of the study population, immunological and genetic factors, cultural beliefs, and socioeconomic characteristics, among others. Immunological and genetic reasons are some of the contributory factors that may explain why some populations exposed to the same bacterial etiologic factors did not develop similar pathological conditions $[6,7]$.
Populations with poorer socioeconomic conditions have shown higher prevalence and extent of teeth mortality, which increases with aging [8-10]. The prevalence, extent, and risk indicators for tooth loss were studied in a representative Brazilian population, showing that $94 \%$ of the subjects had experienced tooth loss [8]. The authors verified a tooth mortality mean of 11.2 , ranging from 5.5 to 20.2 teeth in subjects from 30 to 39 years old and $60+$ years age groups, respectively; gender, socioeconomic status, cigarette smoking, caries experience, and attachment loss were important risk indicators.

On the other hand, a decline in the tooth loss can be verified in developed countries in the last years $[7,11,12]$, which can be explained by preventive programs and higher accessibility to the oral health care that have been decreasing the extractions $[13,14]$. Brazil is a country in development progress (underdeveloped), and some studies verified the prevalence of tooth extractions in Brazilians [4, 8-10, 15, 16], but few of them have verified the reasons for the tooth 
mortality in this population. Thus, the aim of this study was to describe the epidemiological data of the prevalence and reasons for teeth extractions in a convenience sample of Brazilians.

\section{Materials and Methods}

2.1. Sample Selection. This study was approved by the Ethics Committee in Human of Araraquara Dental School (UNESP-process number 45/99). A review of 800 clinical records was performed to select 439 patients with tooth loss from 1999 up to 2002 in Dental Clinics at State University of São Paulo (UNESP), Araraquara city, Brazil (Sudeste region). From the 800 clinical records, 361 subjects were excluded by X-ray absence or absence of specifications of the reasons for tooth mortality, and 439 patients were enrolled in this study. From these 439 patients, 800 teeth with X-ray and specifications of reasons for tooth loss were selected.

2.2. Data Collection. The clinical records were evaluated considering the gender and the age groups. Additionally, the prevalence of tooth loss was evaluated by reasons of extractions and type of teeth (molars, premolars, incisors and canines). The incisors, and canines were nominated only as anterior teeth. The reasons for teeth mortality were adapted based on Cahen et al. [17] as follows: (1) caries: it is properly caries; (2) endodontic problems, such as pulp inflammation, necrosis, or even tooth fracture; (3) periodontal diseases: tooth extraction by periodontal attachment loss; (4) eruption problems: tooth loss by dental impacation; (5) prosthetics: indication for extraction by prosthetic reasons; (6) trauma: extractions by external trauma; (7) orthodontics: tooth extraction by orthodontic indications; (8) occlusal problems: extractions by occlusal dysfunction, such as extrusion; (9) other reasons: any other determined reasons, such as iatrogenic factors. A single examiner accomplished the clinical records assessment, and data was described in a proper form.

2.3. Statistical Analysis. Descriptive data were expressed by means of numbers and percentages. Chi-square statistics $\left(\chi^{2}\right)$ were applied, considering $P<0.05$ as a statistical significant difference. Adjusted residual chi-square $\left(\chi^{2}\right)$ was calculated, considering $1.96(\alpha=0.05)$ and $2.573(\alpha=0.01)$.

\section{Results}

Table 1 shows the data collected from 1999 to 2002, the number of subjects, and teeth included in this study. The number of subjects according to age groups and gender ratio can be verified in Table 2, that shows a similar prevalence of tooth loss between gender in all age groups $(P=0.67)$. Table 3 shows that the groups with range from 35 to 44 years, 45 to 54 years, and 55 to 64 years revealed significantly greater number of teeth extractions than other age groups $(P<0.0001)$. The anterior teeth loss increased with aging and the extractions of premolars and molars decreased with aging, while the tooth mortality of premolar and molar were
TABLE 1: Data collected for the study in different years.

\begin{tabular}{cccc}
\hline Years & $\begin{array}{c}\text { Subjects } \\
\text { (number) }\end{array}$ & $\begin{array}{c}\text { Teeth } \\
\text { (number) }\end{array}$ & $\begin{array}{c}\text { Mean number of teeth } \\
\text { per subject }\end{array}$ \\
\hline 1999 & 138 & 274 & 2.0 \\
2000 & 151 & 239 & 1.6 \\
2001 & 127 & 235 & 1.9 \\
2002 & 23 & 52 & 2.3 \\
\hline Total & 439 & 800 & 1.8 \\
\hline
\end{tabular}

TABle 2: Number of subjects according to age groups and gender ratio $(n=439)$.

\begin{tabular}{lcc}
\hline Age group (years) & Gender* (male/female) & Total \\
\hline $15-19$ & $15 / 16$ & 31 \\
$20-24$ & $12 / 15$ & 27 \\
$25-29$ & $13 / 10$ & 23 \\
$30-34$ & $21 / 17$ & 38 \\
$35-44$ & $34 / 24$ & 58 \\
$45-54$ & $45 / 32$ & 77 \\
$55-64$ & $55 / 39$ & 94 \\
$65-74$ & $28 / 31$ & 59 \\
$75-84$ & $14 / 18$ & 32 \\
\hline$P$ value & 0.67 & - \\
\hline * Chi-square test for categorical data in different age groups $(P$ value $>0.0 .5$ \\
does not indicate statistically significant difference).
\end{tabular}

higher in younger people (Table 4). The results showed that caries and periodontal diseases were statistically significant reasons for tooth loss when compared to the other factors $(P<0.0001 ;$ Table 5). Table 6 shows that caries was the most prevalent reason for tooth mortality among young and adults up to 44 years old, while the periodontal disease was the main reason for extractions from 45 years old until range of 81 years. Other reasons for teeth extractions can be verified as follows: iatrogenic factors (9.9), eruption problems (6.4), orthodontics (5.7), prosthetic indication (3.6), trauma (2.6), and occlusion problems (1.1). It can be seen in Table 6 that tooth mortality for some reasons such as orthodontic, occlusal problems, and other reasons was significantly higher $(P<0.0001)$ among younger, and by prosthetic reasons was significantly higher in older people $(P<0.0001)$.

\section{Discussion}

Our data showed that the number of male and female subjects with tooth loss was similar among all age groups. Conversely, the study by Barbato et al. [10] verified higher prevalence of tooth mortality in women than in men. Other studies assessed the tooth mortality among the urban and rural adult population of Dharwad district (India) in 1223 subjects (685 urban and 538 rural) and found that females compared to males had higher tooth loss [18]. Moreover, our findings showed that the age group between 35 to 44 years old presented a mean tooth loss of 2.3 , which was lower than the 
TABle 3: Number and percentage (\%) of teeth extractions by age group.

\begin{tabular}{lccc}
\hline Age group & $\begin{array}{c}\text { Number } \\
\text { of teeth }\end{array}$ & $\begin{array}{c}\text { \% of teeth } \\
\text { extracted }\end{array}$ & $\begin{array}{c}\text { Mean number of } \\
\text { teeth extracted }\end{array}$ \\
\hline $15-19$ & 64 & 8.0 & 2.1 \\
$20-24$ & 51 & 6.4 & 1.9 \\
$25-29$ & 24 & 3.0 & 1.0 \\
$30-34$ & 45 & 5.6 & 1.2 \\
$35-44^{*}$ & 131 & 16.4 & 2.3 \\
$45-54^{*}$ & 163 & 20.4 & 2.2 \\
$55-64^{*}$ & 180 & 22.5 & 1.9 \\
$65-74$ & 105 & 13.1 & 1.8 \\
$75-84$ & 37 & 4.6 & 1.2 \\
\hline $15-81$ & 800 & 100.0 & 1.8 \\
\hline
\end{tabular}

Chi-square test $\left(\chi^{2}\right)=P<0.0001 .^{*}>2.576(\alpha=0.01)$ adjusted residual chi-square.

Table 4: Prevalence (\%) of extractions by age group and type of teeth.

\begin{tabular}{|c|c|c|c|c|}
\hline \multirow[b]{2}{*}{ Age group } & \multicolumn{4}{|c|}{ Tooth } \\
\hline & $\begin{array}{l}\text { Anterior } \\
N(\%)\end{array}$ & $\begin{array}{c}\text { Premolar } \\
N(\%)\end{array}$ & $\begin{array}{l}\text { Molar } \\
N(\%)\end{array}$ & $\begin{array}{c}\text { Total } \\
N\end{array}$ \\
\hline $15-19$ & - & $33(51.6)^{*}$ & $31(48.4)^{*}$ & 64 \\
\hline $20-24$ & $3(5.9)$ & $22(43.1)$ & $26(51.0)^{*}$ & 51 \\
\hline 25-29 & $5(20.8)$ & $8(33.3)$ & $11(45.9)$ & 24 \\
\hline 30-34 & $11(24.4)$ & $14(31.1)$ & $20(44.5)$ & 45 \\
\hline $35-44$ & $33(25.2)$ & $42(32.1)$ & $56(42.7)^{*}$ & 131 \\
\hline $45-54$ & $62(38.0)$ & $54(33.2)$ & $47(28.8)$ & 163 \\
\hline 55-64 & $84(46.7)^{*}$ & $52(28.9)$ & $44(24.4)$ & 180 \\
\hline $65-74$ & $69(65.7)^{*}$ & $25(23.8)$ & $11(10.5)$ & 105 \\
\hline $75-84$ & $25(67.6)^{*}$ & $7(18.9)$ & $5(13.5)$ & 37 \\
\hline $15-81$ & $292(36.5)$ & $257(32.1)$ & $251(31.4)$ & 800 \\
\hline
\end{tabular}

Chi-square test $\left(\chi^{2}\right)=P<0.0001 .{ }^{*}>2.576(\alpha=0.01)$ adjusted residual chi-square.

mean of 11 verified in the other study [10]. This difference could be explained by the sample size of the studies, which was of 439 Brazilians in our sample and a major population of 13.431 Brazilians in the study by Barbato et al. [10].

Our findings showed that among adolescents aged from 15 to 19 years, the prevalence of tooth extraction was $8.0 \%$, while in a greater population of 16.833 Brazilian adolescents it was $38.9 \%$ [19]. Probably this difference could also be related to the sample size of the studies that is too discrepant. The results in the present study demonstrated higher missing teeth for premolars (43.1 to 51.6\%) and molars (48.4 to $51.0 \%$ ) among the youngest subjects (15 to 24 years), and the dental caries was the main reason for teeth extractions $(67.2 \%)$. Our findings are in agreement with previous studies that have demonstrated that the first molars were the most prevalent missing teeth in Brazilian younger people $[9,15$, 19]. Barbato and Peres [19] found more than $55 \%$ of missing
TABLE 5: Reasons for teeth extractions ( $N$ : number; \% percentage).

\begin{tabular}{lcc}
\hline \multirow{2}{*}{ Reasons } & \multicolumn{2}{c}{ Frequency } \\
& $N$ & $\%$ \\
\hline Caries & $307^{*}$ & 38.4 \\
Periodontal diseases & $258^{*}$ & 32.3 \\
Eruption problems & 51 & 6.4 \\
Prosthetics & 29 & 3.6 \\
Trauma & 21 & 2.6 \\
Orthodontics & 46 & 5.7 \\
Occlusal problems & 9 & 1.1 \\
Others reasons-iatrogenic and accidental & 79 & 9.9 \\
\hline Total & 800 & 100.0 \\
\hline
\end{tabular}

Chi-square test $\left(\chi^{2}\right)=P<0.0001 .{ }^{*}>2.576(\alpha=0.01)$ adjusted residual chi-square.

first molars, and dental caries experiences were found in $92.71 \%$ of all teeth lost. Other studies also suggested that the first molars were the most frequently missing teeth in subjects aged from 14 to 29 [9] and from 13 to 16 years [15].

The caries (38.4\%) and periodontal disease (32.3\%) were the most prevalent conditions for tooth mortality in the present study with similar prevalence. Conversely, other study on Brazilians suggested that the main reason for tooth extraction was the caries $(70.3 \%)$ and not the periodontal disease $(15.1 \%)$, but this study showed findings of a small sample with 404 teeth extracted [16]. In a Caribbean population-Antigua, Viagnarajah [20] also suggested that caries was the main reason for tooth extraction $(61.6 \%)$, and the periodontal disease was the next more frequent reason for tooth loss (29.9\%).

Our results showed that periodontal disease was more prevalent among older subjects over 40 years of age. Some studies are in agreement with our findings, showing that periodontitis became the most prevalent reason for tooth mortality in people near 40 years old [10, 20-26]. In addition, other reasons for teeth extractions were found in the present study as follows: iatrogenic factors (9.9\%), eruption problems $(6.4 \%)$, orthodontics $(5.7 \%)$, prosthetic indication (3.6\%), trauma (2.6\%), and occlusal problems (1.1\%). Caldas [16] also evaluated other reasons for extractions in 404 teeth, such as prosthetic reasons (6.4\%), third molareruption disorders $(3.7 \%)$, orthodontic reasons $(2.5 \%)$, and trauma or patient's request (1\%), which showed lower prevalence than the caries and periodontal disease.

Considering that few studies evaluated reasons for teeth losses in Brazilians, our retrospective study may be useful in clinical dentistry and used as baseline data regarding prevalence and reasons for teeth extractions in other populations; moreover, other prospective studies might be performed.

\section{Conclusions}

Within the limits of this study, it can be suggested that some reasons for tooth loss were age dependent, but the caries and the periodontal diseases were the main reasons for tooth mortality in this Brazilian sample. 
TABLE 6: Reasons for tooth extraction by age groups.

\begin{tabular}{|c|c|c|c|c|c|c|c|c|c|}
\hline \multirow{3}{*}{ Age group } & \multicolumn{9}{|c|}{ Reasons } \\
\hline & $\mathrm{C}$ & PD & E & $\mathrm{P}$ & $\mathrm{T}$ & $\mathrm{O}$ & $\mathrm{OP}$ & Others & Total \\
\hline & $N(\%)$ & $N(\%)$ & $N(\%)$ & $N(\%)$ & $N(\%)$ & $N(\%)$ & $N(\%)$ & $N(\%)$ & $10 \mathrm{ta}$ \\
\hline \multirow{2}{*}{$15-19$} & 43 & - & 18 & - & - & - & - & 3 & 64 \\
\hline & $(67.2)^{*}$ & & $(28.1)^{*}$ & & & & & $(4.7)$ & 04 \\
\hline \multirow{2}{*}{ 20-24 } & 18 & - & 24 & - & - & 4 & - & 5 & 51 \\
\hline & (35.3) & & $(47.1)^{*}$ & & & (7.8) & & (9.8) & \\
\hline \multirow{2}{*}{$25-29$} & 12 & - & 5 & - & - & - & - & 7 & 24 \\
\hline & $(50.0)$ & & $(20.8)^{*}$ & & & & & $(29.2)^{*}$ & 24 \\
\hline \multirow{2}{*}{$30-34$} & 13 & 6 & 2 & - & 2 & 8 & 4 & 10 & 45 \\
\hline & $(28.9)$ & $(13.3)$ & (4.4) & & (4.4) & $(17.8)^{*}$ & $(8.9)^{*}$ & $(22.2)^{*}$ & $4 J$ \\
\hline \multirow{2}{*}{$35-44$} & 73 & 34 & - & - & 2 & - & 2 & 20 & 131 \\
\hline & $(55.7)^{*}$ & $(26.0)$ & & & (1.5) & & (1.5) & $(15.3)^{*}$ & 101 \\
\hline \multirow{2}{*}{$45-54$} & 57 & 63 & - & 7 & 8 & 10 & - & 18 & 163 \\
\hline & $(35.0)$ & $(38.7)^{*}$ & & (4.3) & (4.9) & (6.1) & & $(11.0)$ & \\
\hline \multirow{2}{*}{$55-64$} & 56 & 83 & 2 & 8 & 6 & 13 & 3 & 9 & 100 \\
\hline & $(31.1)$ & $(46.1)^{*}$ & (1.1) & (4.5) & (3.3) & $(7.2)$ & (1.7) & $(5.0)$ & 180 \\
\hline \multirow{2}{*}{$65-74$} & 23 & 54 & - & 10 & 3 & 11 & - & 4 & 105 \\
\hline & (21.9) & $(51.4)^{*}$ & & $(9.5)^{*}$ & (2.9) & (10.5) & & (3.8) & 100 \\
\hline \multirow{2}{*}{$75-84$} & 12 & 18 & - & 4 & - & - & - & 3 & 37 \\
\hline & (32.4) & $(48.7)^{*}$ & & (10.8) & & & & (8.1) & 31 \\
\hline $15-81$ & 38.4 & 32.3 & 6.4 & 3.6 & 2.6 & 5.7 & 1.1 & 9.9 & 800 \\
\hline
\end{tabular}

C: caries; PD: periodontal disease; E: eruption problems; P: prosthetics; T: trauma; O: orthodontics; OP: occlusal problems; Others: other reasons (accidents or iatrogenic factors). Chi-square test $\left(\chi^{2}\right)=P<0.0001 .^{*}>2.576(\alpha=0.01)$ adjusted residual chi-square.

\section{Conflict of Interests}

The authors declare that they have no conflict of interests.

\section{References}

[1] B. D. Moen, "Bureau of Economic Research and Statistics: survey of needs for dental care. II. Dental needs according to age and sex of patients," Journal of the American Dental Association, vol. 46, no. 2, pp. 200-211, 1953.

[2] L. J. Coxhead, "Reasons for extractions in general practice," New Zealand Dental Journal, vol. 56, pp. 182-183, 1960.

[3] C. Lundqvist, "Tooth mortality in Sweden. A statistical survey of tooth loss in the Swedish population," Acta Odontologica Scandinavica, vol. 25, no. 3, pp. 298-322, 1967.

[4] F. A. Machado, H. A. Godoy, A. J. S. Terra, and C. Marzola, "Principais causas das exodontias no município de Campo Grande, MT," Arquivos do Centro de Estudos da Faculdade de Odontologia da Universidade Federal de Minas Gerais, vol. 10, pp. 129-151, 1973 (Portuguese).

[5] I. D. M. Macgregor, "The pattern of tooth loss in a selected population of Nigerians," Archives of Oral Biology, vol. 17, no. 11, pp. 1573-1582, 1972.

[6] M. C. Downer, "The improving dental health of United Kingdom adults and prospects for the future," British Dental Journal, vol. 170, no. 4, pp. 154-158, 1991.

[7] S. E. Marcus, T. F. Drury, L. J. Brown, and G. R. Zion, “Tooth retention and tooth loss in the permanent dentition of adults: United States, 1988-1991," Journal of Dental Research, vol. 75, pp. 684-695, 1996.

[8] C. Susin, R. V. Oppermann, O. Haugejorden, and J. M. Albandar, "Tooth loss and associated risk indicators in an adult urban population from south Brazil," Acta Odontologica Scandinavica, vol. 63, no. 2, pp. 85-93, 2005.

[9] C. Susin, A. N. Haas, R. V. Opermann, and J. M. Albandar, "Tooth loss in a young population from south Brazil," Journal of Public Health Dentistry, vol. 66, no. 2, pp. 110-115, 2006.

[10] P. R. Barbato, H. C. M. Nagano, F. N. Zanchet, A. F. Boing, and M. A. Peres, "Tooth loss and associated socioeconomic, demographic, and dental-care factors in Brazilian adults: an analysis of the Brazilian Oral Health Survey, 2002-2003," Cadernos de Saude Publica, vol. 23, no. 8, pp. 1803-1814, 2007.

[11] T. Hiidenkari, T. Parvinen, and H. Helenius, "Edentulousness and its rehabilitation over a 10 -year period in a Finnish urban area," Community Dentistry and Oral Epidemiology, vol. 25, no. 5, pp. 367-370, 1997.

[12] A. L. Suominen-Taipale, P. Alanen, H. Helenius, A. Nordblad, and A. Uutela, "Edentulism among Finnish adults of working age, 1978-1997," Community Dentistry and Oral Epidemiology, vol. 27, no. 5, pp. 353-365, 1999.

[13] H. Löe, "Ural hygiene in the prevention of caries and periodontal disease," International Dental Journal, vol. 50, no. 3, pp. 129-139, 2000.

[14] O. Haugejorden and K. S. Klock, "Expectation of retaining natural teeth for a lifetime and its predictors among Norwegian adults," Community Dental Health, vol. 19, no. 2, pp. 7378, 2002.

[15] P. Gjermo, M. I. Beldi, H. T. Bellini, and C. R. Martins, "Study of tooth loss in an adolescent Brazilian population," Community Dentistry and Oral Epidemiology, vol. 11, no. 6, pp. 371-374, 1983.

[16] A. F. Caldas Jr., "Reasons for tooth extraction in a Brazilian population," International Dental Journal, vol. 50, no. 6, pp. 267-273, 2000. 
[17] P. M. Cahen, R. M. Frank, and J. C. Turlot, "A survey of the reasons for dental extractions in France," Journal of Dental Research, vol. 64, no. 8, pp. 1087-1093, 1985.

[18] R. Kalyanpur and K. V. Prasad, "Tooth mortality and prosthetic treatment needs among the urban and rural adult population of Dharwad district, India," Oral Health \& Preventive Dentistry, vol. 9, pp. 323-328, 2011.

[19] P. R. Barbato and M. A. Peres, "Tooth loss and associated factors in adolescents: a Brazilian population-based oral health survey," Revista de Saude Publica, vol. 43, no. 1, pp. 13-25, 2009.

[20] S. Vignarajah, "Various reasons for permanent tooth extractions in a Caribbean population-Antigua," International Dental Journal, vol. 43, no. 3, pp. 207-212, 1993.

[21] C. M. Belting, M. Massler, and I. Schour, "Prevalence and incidence of alveolar bone disease in men," Journal of American Dental Association, vol. 47, pp. 190-197, 1953.

[22] W. A. Bossert and H. H. Marks, "Prevalence and characteristics of periodontal disease in 12, 800 persons under periodic dental observation," Journal of American Dental Association, vol. 52, pp. 429-442, 1956.

[23] R. C. Oliver and L. J. Brown, "Periodontal diseases and tooth loss," Periodontology 2000, vol. 2, pp. 117-127, 1993.

[24] E. Reich and K. A. Hiller, "Reasons for tooth extraction in the western states of Germany," Community Dentistry and Oral Epidemiology, vol. 21, no. 6, pp. 379-383, 1993.

[25] G. Ong, "Periodontal reasons for tooth loss in an Asian population," Journal of Clinical Periodontology, vol. 23, no. 4, pp. 307-309, 1996.

[26] L. A. Chambrone and L. Chambrone, "Tooth loss in wellmaintained patients with chronic periodontitis during longterm supportive therapy in Brazil," Journal of Clinical Periodontology, vol. 33, no. 10, pp. 759-764, 2006. 


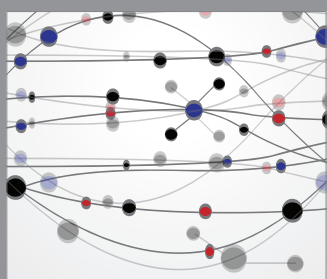

The Scientific World Journal
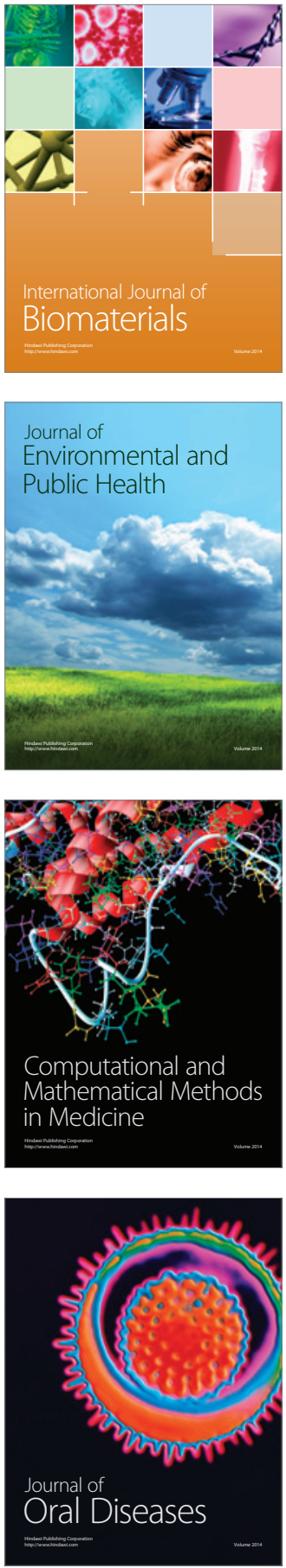
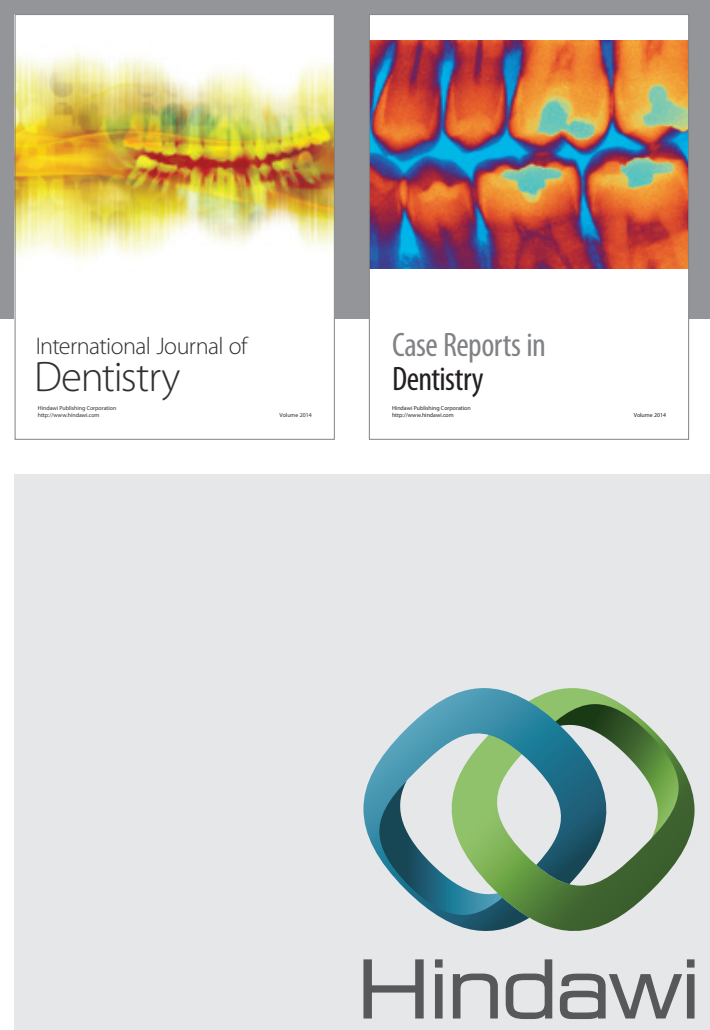

Submit your manuscripts at

http://www.hindawi.com
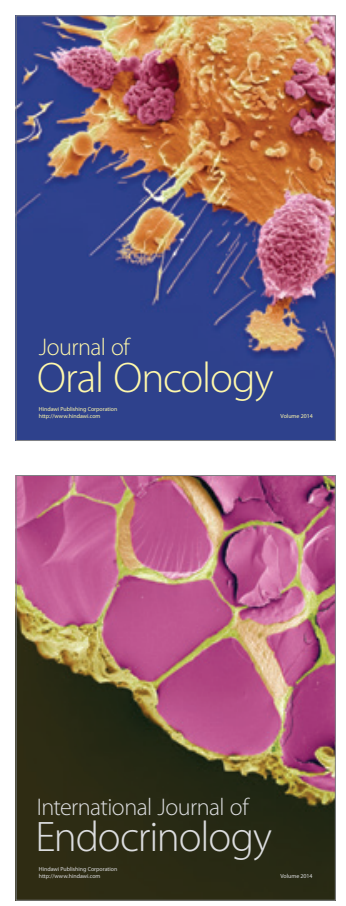
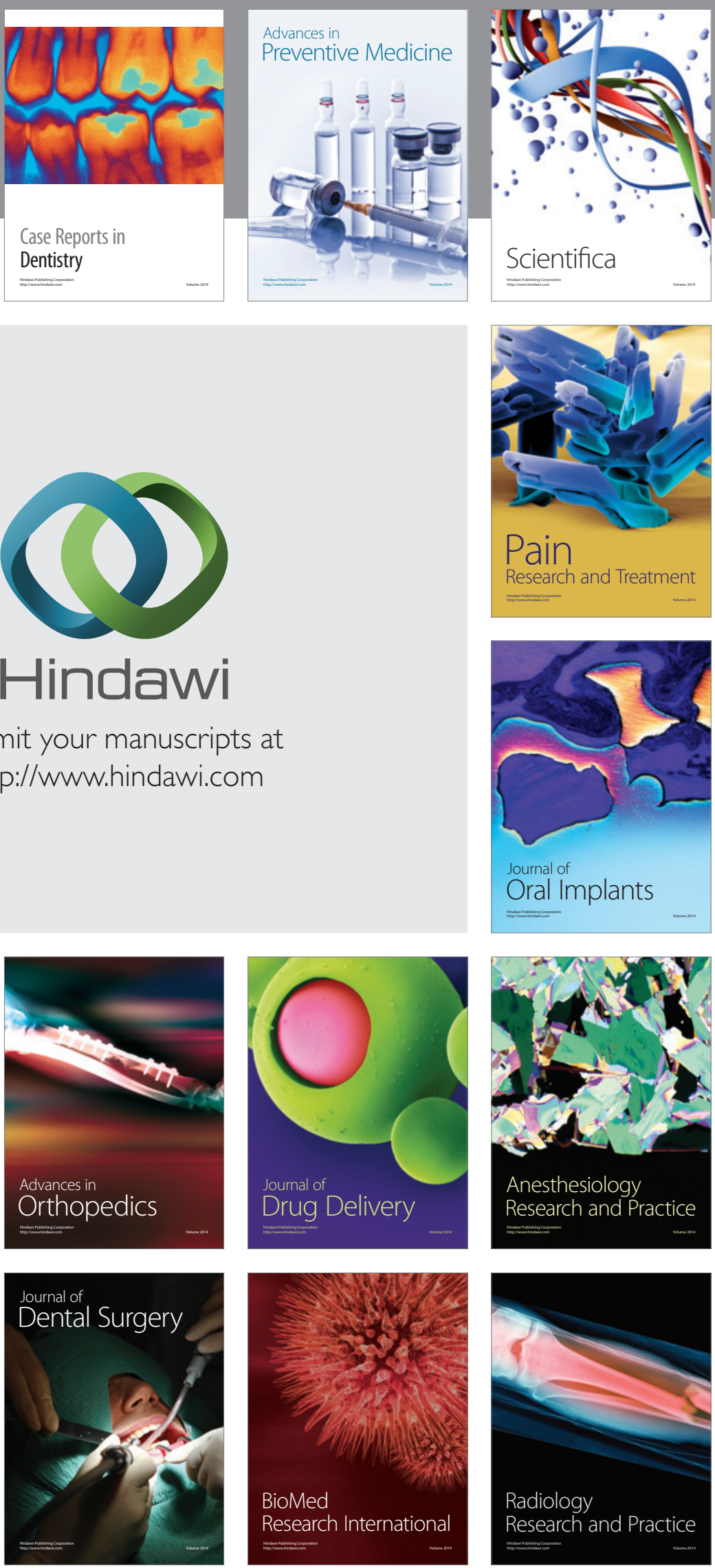